\title{
FEMINIZAR É PRECISO por uma cultura filógina
}

\author{
Margareth Rago \\ Professora do Departamento de História da Unicamp. \\ Autora de Entre a história e a liberdade. Luce Fabbri e o anarquismo contemporâneo
}

\begin{abstract}
Resumo: Este texto traz algumas reflexões sobre o lugar do feminino em nossa cultura, tomando como ponto de partida a recorrente estigmatização da feminista como frustrada, assexuada e mal-amada. Pergunta pelas reações misóginas que a luta pela emancipação das mulheres tem provocado ao longo de sua história e sugere alternativamente a possibilidade da construção de uma cultura filógina.

Palavras-chaves: feminismo; poder; discurso médico; sexualidade; filoginia.
\end{abstract}

Ouso dizer que às vezes você se espanta com minha maneira independente de andar pelo mundo como se a natureza me tivesse feito de seu sexo, e não do da pobre Eva. Acredite em mim, querido amigo, a mente não tem sexo, a não ser aquele que o hábito e a educação lhe dão.

Frances Wright, feminista inglesa, em 1822 (Gay, 1995:306)

$\mathrm{E}$ m um conto intitulado "Jornal de uma feminista", publicado num livro bastante raro, intitulado Almas complexas, a escritora gaúcha Carmen Dolores (1934) delineia uma imagem triste e patética da feminista. Refere-se a uma professora que vive no limite de suas possibilidades financeiras, ao lado da mãe viúva e dos irmãos pequenos e que, certo dia, se vê absolutamente sem recursos para enfrentar o cotidiano. Sentada diante do espelho, enquanto conversa consigo mesma, mal consegue suportar a própria imagem refletida. Sente-se um absoluto fracasso: os seus esforços de melhoria vão sempre por água abaixo; suas lutas são sempre inglórias. Pensa desolada: "Fito os olhos no vidro sarapintado pelas falhas do aço, fui-me sentindo pouco a pouco penetrada de uma piedade intensa e dolorosa, que me provocava a figura refletida nesse velho cristal; fiquei a olhá-la, como se não a conhecesse, assim, magra e abatida, com esse chapéu usado, essa jaquette surrada, correndo tão cedo à caça do pão - e de súbito um véu se interpôs entre mim e a face murcha que eu contemplava, e esse véu era feito de lágrimas...
Lágrimas! Mas por ventura chora uma feminista? Quando muito faz rir, quando passa pelas ruas a passo dobrado, consultando as horas como um homem, sem sorrir, porque já não tem sorriso sem faceirice, porque a fealdade das roupas lha veda, e sem o aprumo que devia dar-lhe o sentimento da sua coragem e da sua dignidade, por que sabe que estas coisas só merecem do vulgo o escárneo..." (Dolores, 1934:123). ${ }^{1}$

Embora construída por uma escritora bastante engajada nas questões da mulher, logo após a conquista do direito de voto feminino, esta imagem reforça o estereótipo socialmente difundido da feminista como uma figura dessexualizada, amargurada e sem perspectivas e, ao mesmo tempo, contrasta com as representações veiculadas pelas revistas feministas do período, ou com as informações referentes à vida cotidiana das escritoras, articulistas e ativistas políticas dos meios ricos e pobres, que se colocavam em luta pela independência de seu gênero, desde meados do século XIX, no Brasil.

Foi esta, pois, a imagem da feminista que predominou na memória social sobre outras possíveis e, ainda hoje, as que lutam pela autonomia das mulheres continuam sendo desqualificadas por um estereótipo que vem de longa data, não apenas dos anos 70, definindo-as como machas, feias e mal-amadas. Do modernista Oswald de Andrade que ridiculariza as sufragettes inglesas como figuras que o assustavam profundamente, nos anos 20, aos "rapazes" de 
esquerda do Pasquim, nos anos 70, investindo com unhas e dentes contra a estética de Betty Friedan, as feministas foram percebidas como mulheres feias, infelizes, sexualmente rejeitadas pelos homens e, convenhamos, não é muito raro ouvirmos outras mulheres reafirmando estes estigmas ainda hoje. ${ }^{2}$

Deve-se perguntar, então, a que vem a perpetuação desse estigma sobre mulheres que lutam e lutaram por outras mulheres, que se empenham pela melhoria da condição feminina, que dão visibilidade a questões radicalmente novas, que propõem outras alternativas para o pensamento e que, sem dúvida alguma, ajudam a construir um mundo novo e muito mais saudável também para os homens? E mais, o que a utilização desse estigma nos informa sobre o lugar do feminino em nossa cultura e sobre a relação que se mantém com o diferente? A reflexão sobre essas questões nos ajuda a perceber como a sociedade reage ante a idéia de que as mulheres passem a se pensar com autonomia, como podendo figurar por conta própria na História, recusando-se a girar, como auxiliares ou sombras, em torno dos homens.

A persistente associação da feminista com o lesbianismo, a histeria, o "furor uterino", a incapacidade de ser amada por um homem, repondo-se todas as misóginas concepções vitorianas sobre a sexualidade feminina, marcam profundamente a referência pela qual se lida com o fenômeno, ainda hoje. Essa questão adquire maior importância quando levamos em conta que o feminismo colocou como uma de suas principais bandeiras as "políticas do corpo", o direito ao próprio corpo, a reivindicação do prazer sexual para as mulheres e que, aliás, progrediu nessa direção.

As críticas às misóginas leituras médicas do corpo feminino, que dessexualizaram e patologizaram cientificamente o corpo da mulher, foram manifestadas, embora por uma minoria, desde o século passado, ou seja, desde o momento mesmo em que estavam sendo formuladas e divulgadas. A redescoberta do clitóris, no final dos anos 60 , foi inegavelmente uma conquista feminista, posteriormente apropriada por revistas femininas de grande circulação no mercado, a exemplo da Nova, lançada em 1972, pela Editora Abril Cultural, ou a Veja, que dá visibilidade ao tema, em sua edição de maio de 2001.

Hoje, as feministas colocam como uma das mais importantes bandeiras de luta a questão dos direitos reprodutivos, aí incluindo-se temas como maternidade, aborto, violência doméstica e saúde integral da mulher. Por que, então, as feministas têm sido historicamente dessexualizadas, se na prática têm reivindicado uma maior sexualização ou, em outros termos, o direito à própria sexualidade?

Trata-se, sem dúvida, de uma disputa pelo controle do que significa ser mulher, mulheres e homens propondo interpretações historicamente muito diferentes e opostas. É óbvio que uma das questões centrais do feminismo, antes e agora, tem sido a de propor a construção de identidades femininas sob outras bases e parâmetros conceituais. Uma recusa, portanto, das formas de sujeição impostas pelo olhar masculino, pela ciência, pela moral e pela cultura masculinas, principalmente nas últimas décadas em que cresce a luta mais pela "desidentificação", ou pela possibilidade de construção de múltiplas subjetividades pessoais, grupais, sexuais. ${ }^{3}$

É de se perguntar, portanto, a que vêm essas construções misóginas e por que foram e são amplamente aceitas? Como se explica que as feministas, que lutaram pela redescoberta da sexualidade feminina, fossem tachadas de dessexualizadas ou, no limite, de lésbicas? Será que essas imagens se ancoravam em amplas constatações empíricas, isto é, eram todas as feministas virgens solteironas ou homossexuais? E, afinal, por que até mesmo as mulheres, nem todas evidentemente, mas sobretudo as das gerações mais jovens não reconhecem o muito do que hoje se conquistou, as enormes possibilidades econômicas, sociais, sexuais e políticas abertas às mulheres, especialmente nas últimas três décadas, desde os direitos civis à revalorização do corpo e à autonomia sexual, como um resultado das pressões e lutas colocadas historicamente pelo feminismo?

Como historiadora feminista, inquieta-me a maneira pela qual determinadas dimensões do passado são totalmente esquecidas, tão logo seus questionamentos tenham sido debatidos, avaliados e incorporados. Isso acontece com alguns pensadores, que, de repente, somem do cenário intelectual e político, enquanto suas idéias, que num momento preciso relampejaram fulminantes, "sacudindo as evidências", como diz Michel Foucault, autonomizamse e passam a ser repetidas localmente, como se nascidas naquele preciso instante ou, então, como se estivessem sempre existido lá. Um fenômeno de autonomização das idéias, em que memória e história se descolam, em que presente e passado se desconectam e se descontextualizam, em que se borram, ou mesmo se perdem os movimentos de origem e as condições de possibilidade de determinados acontecimentos.

Esse processo de eliminação da historicidade dos fenômenos, ou de naturalização pode ser claramente per- 
cebido na relação estabelecida com vários movimentos sociais, entre o feminista, o hippie e o anarquista, entre outros, é claro. Como se se operasse um profundo corte entre gerações imediatamente sucessivas, o que é proposto de maneira impactante e conflituosa por uma, é vivido pelas seguintes com naturalidade, como ordem natural do mundo, esquecendo-se a dimensão da luta realizada para sua conquista e tachando-se o movimento originário de "derrotado".

Nem se está referindo, nessa direção, aos mecanismos já tão discutidos de apropriação e neutralização das reivindicações trabalhistas dos operários das primeiras décadas do século XX pelo governo Vargas, construído como o grande "pai dos pobres", após a destruição desses mesmos movimentos sociais. Penso mais especificamente nas profundas críticas ao movimento hippie dos anos 60/70, visto como "alienado" pela esquerda marxista, radicalmente condenado por ter sido absorvido pelo "sistema". Não se observa, por conseguinte, o quanto a sociedade ganhou e cresceu ao incorporar vários valores, concepções, atitudes e práticas anticapitalistas, libertários e dionisíacos, pregados por aqueles. $\mathrm{O}$ mesmo poderia ser dito em relação ao anarquismo, visto sempre como o "grande derrotado da História", por não haver proposto o partido político, como se afinal os que o propuseram tivessem tido melhor sorte, ou como se a sociedade hoje não fosse muito mais libertária, especialmente no sentido de questionar mais sofisticadamente os macro e micropoderes, as relações de saber-poder, assim como os modos de sujeição, inclusive aqueles impostos pelas organizações partidárias.

Parte-se, evidentemente, do suposto que apesar dos enormes retrocessos e das profundas intolerâncias que atravessam nossos tempos, vivemos também um mundo muito mais libertário e feminista, questionado ininterruptamente em todos os seus movimentos, seguramente há mais de 30 anos.

Em relação ao movimento feminista, não é raro ser considerado atualmente como "coisa do passado" por muitos que se consideram aliviados por seu final, apesar das grandes conquistas femininas em curso e da enorme visibilidade - radiante e colorida -, é bom dizer, das mulheres em quase todas as profissões, na vida social, nas instituições, nos sindicatos, nas ruas, praças e nos bares da cidade. Ninguém duvida de que o mundo se tornou mais feminino e feminista, no Ocidente, entendendo no primeiro caso maior aceitação e reconhecimento da "cultura feminina", de um "saber-fazer" específico das mulheres, mesmo que culturalmente determinado e não resultante de diferenças biológicas; e no segundo caso, referência à luta pelo direito à vida em igualdade de condições para os dois sexos. Aceita-se, em geral, que as mulheres obtiveram inúmeros espaços sociais antes inexistentes ou proibidos para elas, que conquistaram muitos cargos importantes, que provocaram muitas mudanças nas relações de gênero, mudanças que, por sua vez, afetaram a própria maneira de ser homem e de pensar. Contudo, poucas vezes o feminismo é invocado como sendo o produtor principal das mudanças positivas.

Essas constatações têm levado a se tentar entender por que à entrada maciça das mulheres na esfera pública, sobretudo nos últimos 30 anos, à decorrente "feminização da cultura", isto é, à incorporação crescente de valores, idéias, formas, concepções especificamente femininos pelo mundo masculino, não correspondeu uma crescente valorização do feminismo, tanto quanto uma incisiva adesão a ele, seja se for considerado um conjunto de idéias que reivindicam os direitos da mulher, seja como referência às práticas e lutas que eclodiram e têm eclodido na sociedade.

Seria oportuno também refletir, mesmo que brevemente, sobre o tema da "feminização da cultura", questionando os motivos pelos quais frequientemente suscita uma série de objeções, pois não há consenso de que realmente existiu e existe. É de se perguntar, então, se ainda há dúvidas sobre a transformação cultural provocada pela maior inserção das mulheres no mundo contemporâneo. E se ainda há quem pense que as mulheres se tornaram "homens" ao entrar no espaço masculino, esquecendo e abandonando tudo aquilo que caracterizava sua condição de gênero. É possível não perceber a "feminização cultural" contemporânea, isto é, a maneira pela qual temas, valores, questões, atitudes, comportamentos femininos foram incorporados na modernidade? Por que, enfim, esse fenômeno não é percebido como um resultado extremamente positivo das pressões históricas do feminismo, num mundo em que todos reconhecem a falência dos modos cêntricos - faloeuro-etnocêntricos - de agir e pensar?

Não se pretende responder a todas essas questões, mas é importante enunciá-las e denunciar os mecanismos sutis de desqualificação e de humilhação social que operam em nossa cultura, em relação às mulheres e à cultura feminina. Justamente por serem sofisticadas e imperceptíveis a um primeiro olhar, essas estratégias de aniquilamento ou de neutralização das conquistas sexuais e de destruição dos movimentos e das atitudes contestadoras da ordem masculina estabelecida devem ser evidenciadas e enunciadas a cada instante. 


\section{O MEDO DO FEMININO}

\section{E A REAÇÃO MISÓGINA}

Deve-se descartar a primeira resposta, já bem conhecida, "À falocracia, as mulheres propõem a vaginocracia!", e perguntar pelo grande medo do feminino na cultura ocidental, medo este historicizado por intelectuais do porte de Jean Delumeau, Mario Praz e Mireille Dottin-Orsini (1994; 1996; 1996). A punição das feiticeiras pela Inquisição desde a Idade Média, a expropriação do saber das parteiras, desde o século XIX, pela medicina masculina, o alarde em torno da figura da "mulher fatal" destruidora da civilização no século XIX, como Salomé, ou na representação de Marlene Dietrich, no filme $O$ anjo azul, de 1930, concomitante à valorização da "rainha do lar", a perseguição policial das prostitutas e não dos clientes são temas já bem explorados. Falemos, então, das reações ao feminismo, por aí entendendo também o medo provocado pela idéia da liberdade feminina. ${ }^{4}$

Esse movimento, ao lado da crescente entrada das mulheres no mundo público, questionou categorias de significação e explicação sociais amplamente aceitas, mostrando sua dimensão falocêntrica, e provocou uma profunda desestabilização das referências sexuais e culturais ao longo do século XX, em várias partes do mundo. Nas quatro últimas décadas, forçou a incorporação das reivindicações colocadas na agenda pública e obrigou a sociedade a perceber e discutir a "questão feminina". Desestabilizou as tradicionais definições das identidades de gênero - que destinavam rigidamente o espaço público para os homens e o privado para as mulheres -, revelando a hierarquização, as relações de poder e a misoginia nelas contida. Assim, se de um lado abriu novas perspectivas para um amplo setor da humanidade, de outro suscitou profundas angústias e medos em outros setores sociais.

Múltiplas reações se fizeram sentir aos avanços femininos e às conquistas feministas, destacando-se a emergência dos debates sobre a divisão dos papéis sexuais, a preocupação com a definição dos códigos da feminilidade e masculinidade, os direitos e deveres das mulheres, $o$ casamento e o adultério, o controle da prostituição, o perigo da homossexualidade e o próprio feminismo, ao longo do século passado. O clima foi descrito por Elaine Showalter (1994) como sendo de "anarquia sexual". Ante a liberalização dos costumes, a diversificação da vida social e cultural, a emergência de novas práticas de lazer e de novos espaços de sociabilidade, como os bares, restaurantes, cafés-concertos, teatros, cinemas, onde mulhe- res e homens passavam a desfrutar de um convívio mais intenso, desde o início do século XX, inúmeras vozes levantaram-se amedrontadas, apontando para a "dissolução dos costumes" e para o que supunham ser uma forma de desagregação social. Os debates sobre a definição das esferas sexuais, a ameaça de perda de virilidade da civilização, o avanço dos valores femininos na cultura acirraram as controvérsias entre os teóricos da Modernidade, desde meados do século XIX.

$\mathrm{Na}$ belle époque vienense, por exemplo, ao lado de Wagner e Nietszche, Johann Jakob Bachofen, teórico de grande penetração no Brasil e no mundo, autor de $O$ matriarcado. Pesquisas acerca da ginecocracia de natureza reliogiosa e jurídica no mundo antigo, publicado em 1861, atacava radicalmente a feminização da cultura em curso e o "crepúsculo do patriarcado" (apud Le Rider, 1992). Denunciava o amolecimento da raça, a degringolação moral, a degenerescência racial, o retorno à cultura dionisíaca, visando valorizar o patriarcado como "a realização dos valores espirituais trazidos pelo cristianismo." Segundo ele, "O progresso da sensualidade corresponde em toda parte à dissolução das organizações políticas e à decadência da vida pública. No lugar da rica diversidade, impõe-se a lei da democracia, da massa indistinta e essa liberdade, essa igualdade, que distinguem a vida de acordo com a natureza da sociedade civil organizada e que se ligam à parte corporal e material da natureza humana." (apud Le Rider, 1992:179).

Otto Weininger, por sua vez, construiu uma teoria da bissexualização da cultura, movimento que caracterizaria os novecentos como decadência estética e moral.

“A extensão que de alguns anos para cá foi assumida tanto pelo dandismo quanto pelo homossexualismo não podem-se explicar senão por uma feminização geral. Não é sem motivo profundo que o gosto estético e sexual deste início de século busca seus modelos na arte dos prérafaelitas." (apud Le Rider, 1992:176).

Adolf Loos, em artigo sobre a "Moda Feminina", publicado em 1902, procurava explicar porque a mulher tinha mais necessidade de roupas do que o homem, nos seguintes termos:

"Mas, a mulher nua é desprovida de charme para o homem. (...) Este é o motivo que obriga a solicitar a sensualidade do homem através de sua vestimenta, de excitar nele uma sensualidade doentia que resulta unicamente do espírito da época. (...) A roupa da mulher se distingue exteriormente pelos ornamentos e as cores. A mulher se atrasou em relação à evolução da indumentária. No pas- 
sado, o homem também usava vestimentas ricamente ornadas. A evolução magnífica que nossa cultura conheceu durante este século teve o feliz efeito de ultrapassar o ornamento. Quanto mais baixo é o nível de uma cultura, mais o ornamento se manifesta nele com força." (apud Le Rider, 1992:12).

Esses autores, cujos livros se encontram com relativa facilidade nas bibliotecas públicas brasileiras, tiveram uma ressonância bastante grande entre nossos pensadores e governantes, que buscavam nas fontes européias respostas para os problemas do país. Menos conhecidos entre nós foram aqueles que apresentaram questionamentos e respostas alternativas às questões de gênero, a exemplo da feminista Rosa Mayreder, ou do filósofo Georg Simmel, traduzido para o português apenas na década de 90 .

Em seu ensaio de 1905, intitulado Crítica da feminilidade, Mayreder trazia uma nova interpretação sobre as razões da emergência do feminismo. Constatava uma profunda crise da identidade masculina na modernidade e o abandono por parte dos "guerreiros" dos espaços e modelos que tradicionalmente ocupavam. Isso sim estaria levando e até mesmo exigindo maior presença das mulheres na vida pública e social, considerava ela. A emergência do feminismo seria, então, explicada menos como uma luta das mulheres pela liberdade, buscando destronar os homens, do que como resultado da feminização e de um certo refinamento da cultura, que fizera com que a forma masculina de vida se aproximasse da forma de vida das mulheres. Essas, aliás, passavam a ocupar os postos outrora dominados pelos homens, por uma necessidade vital e social, uma vez que eles haviam desertado de seus postos.

"Já que os homens se tornaram mulheres, as mulheres não têm outra escolha senão ocupar o terreno por eles desertado.", afirmava ela (apud Le Rider, 1992:265).

Georg Simmel, por sua vez, em um artigo de 1902, apresentava uma posição menos polarizada e indagava sobre a possível contribuição das mulheres ao participarem de um mundo construído objetiva e racionalmente, segundo a visada masculina. Com um olhar profundamente perspicaz, analisava: “...essa cultura, que é a nossa, se revela inteiramente masculina, com exceção de raros domínios. A indústria e a arte, o comércio e a ciência, a administração civil e a religião foram criação do homem, e não só apresentam um caráter objetivamente masculino, como, ademais, requerem, para a sua efetuação repetida sem cessar, forças especificamente masculinas" (Simmel, 1993:74).
Participando mais intensamente do mundo masculino, as mulheres trariam uma colaboração muito enriquecedora, em função de sua formação e experiência singulares, desconhecidas dos homens, desde que aceitas e reconhecidas. Assim, poderiam oferecer o complemento necessário à cultura dominante, caracteristicamente masculina. Nesse sentido, propunha: "O verdadeiro problema cultural que colocamos assim (produzirá a liberdade que as mulheres buscam novas qualidades culturais) só encontrará resposta positiva mediante uma nova partilha das profissões ou mediante uma nova modulação destas, $f a-$ zendo não que as mulheres se tornem cientistas ou técnicas, médicas ou artistas no sentido em que os homens o são, mas que realizem trabalhos que eles são incapazes de realizar. Trata-se, em primeiro lugar, de estabelecer uma outra divisão do trabalho, de redistribuir os trabalhos globais de uma profissão dada, de reunir depois os elementos especificamente adaptados ao modo de trabalho feminino para constituir esses ofícios parciais, singulares, diferenciados. Não se obteriam, assim, apenas um aperfeiçoamento e um enriquecimento extraordinários de todo o setor de atividade envolvido, mas também se evitaria em boa parte a concorrência dos homens." (grifos meus) (Simmel, 1993:74).

Simmel raciocinava em termos da complementaridade trazida pela experiência feminina, bastante diferenciada da masculina, tanto por questões culturais quanto naturais. $\mathrm{O}$ fato de desacreditarmos hoje da existência de uma suposta "natureza feminina" não invalida suas colocações, afinal as diferenças de gênero, construídas social e culturalmente, marcaram profundamente a formação de nossa identidade ao longo do tempo, assim como a definição dos espaços sociais femininos e masculinos. O filósofo defendia que a luta pela emancipação das mulheres, pela destruição dos preconceitos sexistas, pela igualdade de direitos entre os sexos traria grandes benefícios para a humanidade, pois considerava a cultura masculina como restrita, dura, objetiva e racional, ou seja, excludente de outras importantes dimensões vitais da experiência humana. A entrada das mulheres na vida pública e social poderia, afirmava ele, transformar e enriquecer consideravelmente a maneira de viver, de pensar e de solucionar os problemas individuais e coletivos, inovando em relação aos métodos utilizados e às técnicas produzidas. Num pensamento bastante avançado, pensava muito mais em termos da interação de duas culturas sexualmente determinadas, do que na substituição de uma pela outra. Assim, na medicina, dizia ele, as mulheres dariam uma enor- 
me contribuição, pois tendo um aprendizado diferente de lidar com o corpo e com as emoções, poderiam perceber melhor e mais detidamente o próprio doente.

"Os métodos de exame clínico tidos como objetivos logo se esgotam, se não forem completados por um conhecimento subjetivo do estado do doente e de seus sentimentos, seja esse conhecimento imediatamente instintivo, seja mediatizado por manifestações quaisquer. (...) é por isso que estou persuadido de que, confrontada a mulheres, uma médica, além de ter o diagnóstico mais exato e o pressentimento mais fino para tratar dos casos individuais de maneira conveniente, ainda poderia, sob o ângulo puramente científico, descobrir conexões típicas, não detectáveis por um médico, e dar com isso contribuições específicas à cultura objetiva; porque as mulheres possuem, com sua constituição idêntica, uma ferramenta de conhecimento recusada aos homens." (Simmel, 1993:76).

Na mesma direção, a anarquista italiana Luce Fabbri, desde os anos 30, acreditou que as mulheres podiam dar uma contribuição especial à cultura dominante, justamente por não terem tido a experiência de guerra dos homens, por não terem participado dos governos, dos exércitos, da polícia e por terem desenvolvido uma cultura salutar, ligada aos cuidados com a vida, com a organização doméstica e com a sobrevivência das crianças e velhos. Numa entrevista realizada em 1996, afirmou: “...as mulheres têm algo de seu para dar, algo de gênero, uma experiência única de uma economia não competitiva: a economia doméstica, em que as crianças têm precedência, em que os velhos estão assistidos porque são velhos, em que cada qual dá o que pode e consome o que necessita, isto é a economia doméstica. $^{5}$

No Brasil, infelizmente, as pesquisas históricas referentes aos discursos científicos e políticos predominantes até os anos 60, masculinos, é claro, permitem perceber muito menos os ecos dessas concepções filóginas, na problematização das relações entre os gêneros, do que a acentuação dos discursos misóginos, produzidos e reproduzidos no contexto das discussões sobre os rumos de construção da nação e a formação do povo.

Principalmente a partir da instalação da República, do início da industrialização, da imigração européia maciça e da modernização das cidades, desde o final do século XIX, a maioria dos médicos, juristas, políticos, escritores, jornalistas e ativistas políticos, reagiu muito mais negativamente às transformações que desestabilizavam as relações entre mulheres e homens. Para eles, a desestabilização das antigas fronteiras de gênero destruiria a anti- ga organização familiar e as definições tanto da feminilidade quanto da masculinidade. Muitos reagiam inquietos à emergência das reivindicações feministas, à modernização dos costumes, ao surgimento de novas formas de sociabilidade, ao crescimento das práticas de lazer, dos passeios nas ruas aos novos ritmos musicais e às novidades da moda.

Os médicos tiveram um papel bastante grande na redefinição dos códigos da sexualidade feminina, ao buscar na própria anatomia do corpo da mulher os limites físicos, intelectuais e morais à sua integração na esfera pública. Esforçaram-se para definir a especificidade do corpo feminino em relação ao masculino, acentuando seus principais traços: fraqueza e predestinação à maternidade. Para o importante dr. Roussel, médico iluminista francês, cujas teorias tiveram ampla repercussão no mundo ocidental, na mulher "os ossos são menores e menos duros, a caixa toráxica é mais estreita; a bacia mais larga impõe aos fêmures uma obliqüidade que atrapalha o andar, pois os joelhos se tocam, as ancas balançam para encontrar o centro de gravidade, o andar é vacilante e inseguro, a corrida rápida é impossível às mulheres”, explica Knibiehler (1983:90).

Ademais, os doutores conseguiram ampla penetração social, como inúmeros estudos mostram, interferindo incisivamente na constituição do imaginário social e sexual, sobretudo por apresentarem-se como portadores do discurso científico legítimo, produtor da verdade e das soluções aos problemas da doença e da morte. ${ }^{6}$

Nesse sentido, o saber médico informou uma série de práticas autoritárias e misóginas, que permitiram justificar objetivamente a exclusão das mulheres de inúmeras atividades políticas, econômicas e sociais, para não dizer das sexuais, estigmatizando aquelas que, como as feministas, se colocaram na contramão. Ao mesmo tempo, propôs alternativas para um reajustamento das relações de gênero, mantendo inalteradas as formas da dominação masculina. Segundo a "brasilianista" Susan Besse (1996), as relações sexuais foram modernizadas, nas décadas iniciais do século, tendo em vista atender às necessidades masculinas, mas não acabar com as desigualdades de gênero.

Contudo, o medo e à aversão ao feminino, visto como o grande desconhecido, não impediu a própria transformação da vida social e das formas culturais ao longo de todo o século XX, principalmente em função da crescente entrada das mulheres no mundo público, a partir dos anos 70 . 


\section{DA FEMINIZAÇÃO CULTURAL}

A maneira pela qual a valorização da cultura feminina tem afetado nosso mundo é perceptível em vários momentos, dos quais seria importante apenas sugerir alguns breves exemplos no âmbito da ciência, da política e da sexualidade.

Em relação à produção do conhecimento, sem dúvida alguma a constituição de uma área de "estudos feministas" em quase todas as universidades do mundo ocidental permitiu inovar profundamente não apenas no reconhecimento da participação das mulheres nos processos históricos, mas na crítica à própria narrativa histórica, vista agora como produção sexuada ou "generificada" (gendered). ${ }^{7}$ Da inclusão das mulheres nos acontecimentos políticos e sociais, passou-se a perceber as dimensões femininas da vida humana, antes excluídas do discurso histórico, a exemplo da história da vida privada, da história das sensibilidades, das emoções, dos sentimentos, e de outras dimensões consideradas femininas em nossa cultura (Rago, 1996). E daí perceberam-se praticamente as limitações dos conceitos masculinos, inscritos na lógica da identidade, para representar o "irrepresentável" e, nesse caso, para dar conta das experiências e práticas femininas, ou de outros grupos sexuais.

A epistemologia feminista, como mostra Sandra Harding (1996:13), apontou para a necessidade da descentralização do foco da atenção da masculinidade no interior do pensamento e nas práticas sociais: o masculino, embora instituído culturalmente, deveria deixar de ser o único padrão existente para o assim chamado ser humano, uma vez que os homens não são os únicos habitantes humanos do planeta. Centrar a atenção exclusivamente nas necessidades masculinas, nos seus interesses, desejos, concepções, garante apenas uma compreensão distorcida e parcial das práticas sociais.

$\mathrm{Na}$ área da política, o feminismo questionou, de maneira diferenciada nos seus dois momentos expressivos os anos 20/30 e os anos 60/80 do século passado -, os conceitos básicos que sustentam os princípios liberais, como o universalismo, a idéia de liberdade e igualdade, originados a partir do contrato social, denunciando que este sempre foi formado a partir da exclusão de muitos e que, portanto, a constituição de uma esfera pública autônoma só seria possível pela perspectiva da diferença e não da igualdade. Várias autoras observaram que "os estudos feministas, assim como os estudos étnicos ou antiimperialistas, promovem um deslocamento radical de perspec- tiva ao assumir como ponto de partida de suas análises o direito dos grupos marginalizados de falar e representarse nos domínios políticos e intelectuais que normalmente os excluem, usurpam suas funções de significação e representação e falseiam suas realidades históricas" (Holanda, 1994:8).

Buscando a construção de um novo conceito de cidadania, Sonia Alvarez mostrou como a atuação das mulheres e sua interferência na esfera pública burguesa, no Brasil das últimas décadas, forçou a incorporação de suas demandas, levando a que se ampliasse seu espaço de representação. As mulheres passaram a participar de todos os campos social e político: suas demandas foram levadas aos partidos políticos, às centrais de trabalhadores, aos sindicatos, aos coletivos e criaram-se instituições especificamente voltadas para a questão feminina (Alvarez, 1990; Alvarez e Escobar, 1992). Evidentemente, são muitos os problemas que emergem a partir de então, mas, sem dúvida alguma, a visibilidade que a "questão feminina" ganha não deixa de ser um ponto de partida fundamental para qualquer negociação possível.

Segundo outra feminista, Eleonora Menicucci de Oliveira (1990), as mulheres politizaram praticamente o privado, desfazendo as tradicionais barreiras que opõem o público-masculino ao privado-feminino. Ao trazerem as questões privadas para o espaço público, ao assumirem a discussão pública de sua sexualidade, entre os anos 70 e 80 , forçaram sua incorporação e produziram uma profunda transformação naquilo que era considerado os direitos de cidadania. Nesse sentido, a sexualidade, antes silenciada e considerada questão de pouca importância política e social, foi trazida para o cenário político, levando a uma discussão sobre os pressupostos hierárquicos que regem nossas representações sexuais e nossas definições do lícito e do ilícito para toda a sociedade.

É preciso levar em conta a tradição política autoritária e clientelista de nosso país, onde nunca se formou uma clara noção de esfera pública moderna e de direitos do cidadão. Aqui, as mulheres sempre foram vistas como muito mais irracionais do que os homens pobres, porque foram consideradas como muito mais sensuais e sexualizadas do que as dos países de tradição puritana. Discutir a sexualidade no Brasil é, então, de extrema importância, pois com base no argumento da "sensualidade tropical", característica fundamental das mulheres, das índias nuas às mulatas carnavalescas de Sargentelli, justificou-se a dominação masculina e patriarcal e sua exclusão do mundo dos negócios e da política (Parker, 1993). Lembre-se 
que, poucas décadas atrás, "mulher pública" evocava a prostituta e não uma figura que participava do mundo da política, e que as prostitutas, no passado, também não haviam ainda criado seus movimentos de luta pela cidadania, como o que surge a partir de 1987, nem sugerido a figura da "trabalhadora do sexo" como alternativa política para sua identidade.

O feminismo veio questionar essa leitura hierarquizadora e excludente da política, informada pelo discurso médico masculino, que justificava com base em argumentos científicos a incapacidade física e moral das mulheres para a condução dos negócios da cidade. Mostrou como se opera a exclusão social das mulheres do mundo público, assim como o silenciamento e a desqualificação de seus temas e questões. Lutou e luta para que as mulheres se reconheçam como sujeitos políticos, cidadãs com deveres e direitos a serem reconhecidos e criados. Tem ampliado, portanto, o conceito de cidadania, propondo uma nova concepção da prática política, que se manifesta não apenas nos espaços permitidos e institucionalizados da política, mas na própria vida cotidiana.

Contudo, é importante remontar ao passado e perceber como essa tradição de pensamento se constituiu historicamente, onde e quando as primeiras feministas enunciaram seus temas, revelando a especificidade da condição feminina; onde e quando falaram publicamente sobre a questão da sexualidade, abrindo espaço para sua interferência no público; onde e quando se manifestaram em prol da emancipação feminina e foram silenciadas e excluídas. Se essa crítica foi amplamente formulada nas últimas décadas do século XX pelo movimento feminista, vale lembrar que foi colocada no próprio movimento de constituição da esfera pública, no final do século XIX, e que o silenciamento deste fato pela memória histórica masculina estabelece mais um elemento da exclusão das mulheres do direito de viver com dignidade.

Finalmente, para além do questionamento da política e das restrições da cidadania, o feminismo expandiu sua crítica para as bases de constituição da racionalidade que norteia as práticas sociais e sexuais. Estendeu a crítica às próprias formas da cultura, revelando como a dominação se constitui muito mais sofisticadamente nas próprias formas culturais que instituem uma leitura da política e da vida em sociedade, convergindo com outras correntes do pensamento pós-moderno, como "o pensamento da diferença". ${ }^{8}$ Nesse sentido, longe de pretender destronar o "rei" para colocar em seu lugar uma "rainha", o feminismo propõe a destruição da monarquia no pensamento e nas prá- ticas sociais, inclusive dentro de si mesmo. Afinal, hoje as feministas dificilmente aceitariam falar em nome de um único feminismo, pluralizando, portanto, suas definições e campos de atuação.

\section{POR UM MUNDO FILÓGINO}

Retomando a pergunta inicial: como se explica, então, a atitude antifeminista socialmente difundida e incorporada, mesmo por aquelas que usufruem das conquistas feministas que levaram muitas décadas para se concretizar? Certamente, o mecanismo de naturalização e de cristalização das práticas sociais, que implica sua deshistoricização, é fundamental na configuração do imaginário misógino. De outro modo, como entender esse grande paradoxo que não permite atar nenhum fio com a tradição feminista que herdamos, fazendo supor que um dia o mundo mudou, as portas se abriram para as mulheres e ponto final? Como entender que as mulheres independentes do nosso mundo, sobretudo as jovens, as mais livres, não se identifiquem ou não se sintam em nada devedoras em relação àquelas que lutaram, ou lutam pela abertura do campo de possibilidades de que desfrutam na atualidade, senão por um mecanismo perverso que faz com que tomem como origem o que não deixa de ser efeito produzido cultural e socialmente?

Uma mudança de olhar, um pensamento diferencial poderia dar conta de permitir uma maior sensibilidade em relação ao feminino e à construção de um mundo filógino. Ou será uma questão de coração, mais do que de olhar?

Filoginia, do grego philos, amigo + gyne, mulher - amor às mulheres - antônino Misoginia, aversão às mulheres (Grande Dicionário Larousse, 1999:432).

\section{NOTAS}

1. Sobre as escritoras brasileiras, veja-se o belo estudo de Norma Telles (1986)

2. Oswald de Andrade: "Em Londres, fui encontrar vivas nas ruas duas novidades - o assalariado e a sufragete. Esta era representada por mulheres secas e machas que se manifestavam como se manifestava o operário. Ordenadamente, às vistas da polícia, mas protestando contra um estado de coisas de que minha ignorância mal suspeitava." (1959:69).

3. Veja-se a respeito Costa (1996)

4. Dois importantes trabalhos sobre a história do feminismo no Brasil são: Família e feminismo: reflexões sobre os papéis femininos na imprensa para mulheres (Moraes, 1981) e Feminismo e autoritarismo: a metamorfose de uma utopia de liberação em ideologia liberalizante (Golberg, 1987).

5. Veja-se a respeito Margareth Rago (2001:315).

6. Vejam-se por ex. Meretrizes e doutores (Engel, 1989); e Os prazeres da noite. Prostituição e Códigos da Sexualidade Feminina em São Paulo (Rago, 1991). 
7. Como a bibliografia na área é vastíssima, indicam-se apenas alguns trabalhos muito conhecidos: Gender and the politics of history (Scott, 1988); Gender trouble. Feminism and the subversion of identity e Bodies that matter (Butler, $1991 \mathrm{e}$ 1993); Feminismo como crítica da modernidade (Benhabib, 1991); Poética do pós-modernismo (Hutcheon, 1991); Pós-modernismo e política (Holanda, 1991); Uma questão de gênero (Bruschini e Oliveira, 1990).

8. Susan Bordo (2000) levanta instigantes questões a respeito dessa aproximação, perguntando-se pelos motivos que levam à grande visibilidade dos "filósofos da diferença" em contraste com a invisibilidade das teóricas feministas.

\section{REFERÊNCIAS BIBLIOGRÁFICAS}

ALVAREZ, S. Engendering democracy in Brazil: women's movement in transition politics. Princeton, N.J., Princeton University Press, 1990.

ALVAREZ, S. e ESCOBAR, A. The making of social moviments in latin america: Identity, strategy and democracy. Boulder, Westview Press, 1992.

ANDRADE, O. de. Um homem sem profissão. Sob as ordens de mamãe. Rio de Janeiro, Ed. Civilização Brasileira, 1959.

BENHABIB, S. Feminismo como crítica da modernidade. Rio de Janeiro, Rosa dos Tempos, 1991.

BESSE, S. Restructuring patriarchy. The modernization of gender inequality in Brazil, 1914-1940. The University of North Carolina Press, 1996.

BORDO, S. "A feminista como o outro". Revista Estudos Feministas. Centro de Filosofia e Ciências Humanas da UFSC, v.8, n.1, 2000, p.10-29.

BRUSCHINI, C. e OLIVEIRA, A. Uma questão de gênero. Rio de Janeiro/São Paulo, Ciec/Carlos Chagas, 1990.

BUTLER, J. Gender trouble. Feminism and the subversion of identity. Nova York, Routledge, 1991.

$$
\text { . Bodies that matter. Nova York, Routledge, } 1993 .
$$

COSTA, C.L. "Sujeitos ex/cêntricos: explorando as fronteiras das teorias feministas". Fazendo gênero. Revista da Pós-Graduação em Letras da UFSC, 1996.

DELUMEAU, J. História do medo no ocidente. São Paulo, Companhia das Letras, 1994.

DOLORES, C. Almas complexas. Rio de Janeiro, Editor Calvino Filho, 1934.

DOTTIN-ORSINI, M. A mulher que eles chamam fatal. Rio de Janeiro, Rocco, 1996.

ENGEL, M. Meretrizes e doutores. São Paulo, Ed. Brasiliense, 1989.
GAY, P. A experiência burguesa da Rainha Vitoria a Freud. São Paulo, Companhia das Letras, 1995, v.3: O cultivo do ódio.

GRANDE DICIONÁRIO LAROUSSE CULTURAL DA LÍNGUA PORTUGUESA. São Paulo, 1999.

GOLDBERG, A. Feminismo e autoritarismo: a metamorfose de uma utopia de liberação em ideologia liberalizante. Dissertação de Mestrado. Rio de Janeiro, UFRJ, 1987.

HARDING, S. Whose science? Whose knowledge? Thinking from women's lives. Nova York, Cornell University Press, 1996.

HOLANDA, H.B. Pós-modernismo e política. Rio de Janeiro, Rocco, 1991. Tendências e impasses. O feminismo como crítica da cultura. Rio de Janeiro, Rocco, 1994.

HUTCHEON, L. Poética do pós-modernismo. Rio de Janeiro, Imago, 1991.

KNIBIEHLER, Y. e FOUQUET, C. La femmes et les medecins. Paris, Hachette, 1983.

LE RIDER, J. A modernidade vienense e as crises de identidade. Rio de Janeiro, Civilização Brasileira, 1992.

MORAES, M.L.Q. de. Família e feminismo: reflexões sobre os papéis femininos na imprensa para mulheres. Tese de Doutorado. São Paulo, FFLCH/ USP, 1981.

OLIVEIRA, E.M. de. A reapropriação do corpo feminino: da recusa do confinamento doméstico à invenção de novos espaços de cidadania. São Paulo, Departamento de Ciência Política da USP, 1990.

PARKER, R. Corpos, prazeres e paixões. A cultura sexual no Brasil contemporâneo. São Paulo, Ed. Bestseller, 1993.

PRAZ, M. A carne, a morte e o diabo na literatura romântica. Campinas, Ed. da Unicamp, 1996

RAGO, M. Os prazeres da noite. Prostituição e códigos da sexualidade feminina em São Paulo. Rio de Janeiro, Paz e Terra, 1991.

"Epistemologia feminista, história e gênero". In: GROSSI, M. e PEDRO, J. Masculino, feminino, plural. Florianópolis, Ed. das Mulheres, 1996.

Entre a história e a liberdade. Luce Fabbri e o anarquismo contemporâneo. São Paulo, Ed. da Unesp, 2001.

SCOTT, J. Gender and the politics of history. Nova York, Columbia University Press, 1988.

SHOWALTER, E. Anarquia sexual. Rio de Janeiro, Rocco, 1994.

SIMMEL, G. Filosofia do amor. São Paulo, Martins Fontes, 1993.

TELLES, N. Encantações. Escritoras e imaginação literária no século XIX. Tese de Doutorado, São Paulo, PUC-SP, 1986. 